\title{
Estimation of feed crude protein concentration and rumen degradability by Fourier-transform infrared spectroscopy
}

\author{
A. Belanche, ${ }^{*}$ M. R. Weisbjerg, † G. G. Allison, ${ }^{*}$ C. J. Newbold, ${ }^{*}$ and J. M. Moorby ${ }^{* 1}$ \\ *Institute of Biological, Environmental and Rural Sciences, Aberystwyth University, SY23 3EE, Aberystwyth, United Kingdom \\ †Department of Animal Science, AU Foulum, Aarhus University, DK-8830 Tjele, Denmark
}

\begin{abstract}
Currently, rapid methods are needed for feed analysis. This study examined the potential of Fouriertransform infrared (FTIR) spectroscopy to predict the nutritional value of a wide range of feeds for ruminants, as an alternative to the in situ technique. Moreover, we investigated whether universal equations could be developed that would allow the low-cost determination of crude protein $(\mathrm{CP})$ concentrations and their kinetics of degradation into the rumen. Protein nutritional values of 663 samples comprising 80 different feed types were determined in terms of concentrations of $\mathrm{CP}$, watersoluble $\mathrm{CP}\left(\mathrm{CP}_{\mathrm{WS}}\right)$, total-tract mobile bag $\mathrm{CP}$ digestibility $\left(\mathrm{CP}_{\text {TтD }}\right)$, and in situ $\mathrm{CP}$ degradability, including the rumen soluble fraction $\left(\mathrm{CP}_{\mathrm{A}}\right)$, the degradable but not soluble fraction $\left(\mathrm{CP}_{\mathrm{B}}\right)$, rate of $\mathrm{CP}_{\mathrm{B}}$ degradation $\left(\mathrm{CP}_{\mathrm{C}}\right)$, effective degradability $\left(\mathrm{CP}_{\mathrm{ED}}\right)$, and potential degradability $\left(\mathrm{CP}_{\mathrm{PD}}\right)$. Infrared spectra of dry samples were collected by attenuated total reflectance from 4000 to $600 \mathrm{~cm}^{-1}$. Models were developed by partial least squares (PLS) regression in a randomly selected subset of samples, and the precision of the equations was confirmed by using an external validation set. Analysis by FTIR spectroscopy was sufficiently sensitive to allow the accurate prediction of sample $\mathrm{CP}$ concentration $\left(\mathrm{R}^{2}\right.$ $=0.92)$ and to classify feeds according to their $\mathrm{CP}_{\mathrm{Ws}}$ concentrations using universal models $\left(\mathrm{R}^{2}=0.78\right)$ that included all sample types. Moreover, substantial improvements in predictions were observed when samples were subdivided in groups. Models for forages led to accurate predictions of $\mathrm{CP}_{\mathrm{WS}}$ and fractions $\mathrm{CP}_{\mathrm{A}}$ and $\mathrm{CP}_{\mathrm{B}}\left(\mathrm{R}^{2}>0.83\right)$, whereas models for $\mathrm{CP}_{\text {TTD }}$ and $\mathrm{CP}_{\mathrm{ED}}$ could be used for screening purposes $\left(R^{2}>0.67\right)$. This study showed that models for protein-rich concentrates alone could also be used for screening according to the feed concentrations of $\mathrm{CP}_{\mathrm{WS}}, \mathrm{CP}_{\mathrm{TTD}}, \mathrm{CP}_{\mathrm{ED}}, \mathrm{CP}_{\mathrm{A}}$, and $\mathrm{CP}_{\mathrm{B}}$, but models for energy-rich concentrates gave relatively poor predictions. The general difficulty ob-
\end{abstract}

Received June 12, 2013.

Accepted August 15, 2013.

${ }^{1}$ Corresponding author: jon.moorby@aber.ac.uk served in predicting $\mathrm{CP}_{\mathrm{C}}$ is because of a low correlation between FTIR spectra and the kinetics of CP degradation, which may be the result of large variation in the reference method (i.e., in situ degradation studies) and perhaps also because of the presence of compounds that can modify the CP degradation pattern in the rumen. In conclusion, FTIR spectroscopy should be considered as a low-cost alternative in the feed evaluation industry. Key words: crude protein, Fourier-transform infrared spectroscopy, feed evaluation, rumen degradability

\section{INTRODUCTION}

Due to the presence of symbiotic microbial populations within the rumen, ruminants are the only livestock capable of using cellulose and nonprotein $\mathrm{N}$ efficiently. This evolutionary adaptation substantially increases the diversity of feeds and feed by-products that can be consumed by ruminants, and decreases feed competition with monogastric livestock and humans. The efficiency of dietary $\mathrm{N}$ use for retention in meat, milk, and wool is not optimal, however, and improvements in the feeding evaluation systems for ruminants are required. Traditionally, nutritionists have relied on static models, which take account of the chemical composition of the feeds, to balance rations for ruminants (ARC, 1984). Most modern feed evaluation systems are, however, based on dynamic models in which kinetic parameters of individual nutrients are used for ration balancing (Danfaer et al., 2006). These latter approaches account for the dynamic process of CP degradability in the rumen, which directly influences the quantities of $\mathrm{N}$ available for rumen microbial use and the passage of undegraded $\mathrm{CP}$ through the rumen to the small intestine. However, successful implementation of advanced ration formulation regimens requires the ability to measure or predict the degree of the feed's CP degradation and its digestibility in the intestinal tract.

To determine the characteristics of feed CP degradability in the rumen, the in situ method was used because it is a well-established procedure in which the degradation profile is determined as the progressive feed disappearance from a nylon bag incubated in the ru- 
men. Similarly, the mobile bag technique is recurrently used to determine total-tract digestibility (Hvelplund, 1985). These procedures are chosen as reference methods in several feed evaluation systems for ruminants (Verité and Peyraud, 1989; Madsen et al., 1995; NRC, 2001; Van Duinkerken et al., 2011). Nevertheless, these feed evaluation techniques have several limitations that make them impractical for on-farm conditions because rumen-cannulated animals and substantial labor inputs are required. The availability of a robust, cost-effective technique to evaluate the protein nutritional value in feeds would help farmers and their advisors improve diet formulations under farm conditions.

Infrared (IR) spectroscopy is a technique based on the principle that the type of atoms and atomic bonds within molecules determine the wavenumbers in which the electromagnetic vibrations happen when molecules are excited with a laser. Therefore, analysis of feeds by IR spectroscopy provides chemo-structural information that can be applied by nutritionists and plant breeders using chemometric approaches as an alternative method to traditional ("wet") chemistry. These IR techniques require only relatively small amounts of material and generally allow rapid, low-cost, and robust predictions. To this end, near-IR reflectance spectroscopy (NIRS) has been successfully used to predict feed composition and the kinetics of nutrient degradation in the rumen (Herrero et al., 1997; Andres et al., 2005a; Ohlsson et al., 2007).

Mid-IR spectroscopy scans a wider spectral range than NIRS (600 to $4000 \mathrm{~cm}^{-1}$ vs. 800 to $2500 \mathrm{~cm}^{-1}$, respectively). Moreover, mid-IR spectroscopy, in contrast to NIRS, yields information on fundamental molecular vibrations, rather than on harmonic and overtone absorptions, and gives better insight into the molecular bonds present in a sample. This means that the mid-IR spectrum of a sample should be directly related to its chemical composition. Over recent years, mid-IR spectroscopy has been revolutionized by the development of Fourier-transform infrared (FTIR) spectrometers, which allow greater sensitivity and rapid rates of data acquisition. However, the potential abilities of this technique to predict feed nutritional composition need further investigation.

The objective of the present study was to determine the ability of FTIR spectroscopy to predict the nutritional value of several feedstuffs. We hypothesized that FTIR spectra could be used to develop a universal model that enables the determination of feed CP concentration and the kinetics of rumen CP degradation in feeds. In addition, we investigated the potential advantages of developing specific equations for forages (FOR), energy-rich concentrates (ERC), and proteinrich concentrates (PRC).

\section{MATERIALS AND METHODS}

\section{Sample Composition and Rumen Degradability}

A total of 663 samples, comprising 80 different feed types, were collected over the course of a 10-yr period and used in this study. These samples represent many of the feed types frequently used in ruminant nutrition, such as conserved forages, concentrates, and by-product feeds. Table 1 shows the samples analyzed indicating their botanical or industrial origin. All samples were freeze-dried, milled to pass through a $1.5-\mathrm{mm}$ screen (Pulverisette 15, Fritsch, Idar-Oberstein, Germany), and stored at room temperature in airtight containers until further analysis.

All freeze-dried samples were analyzed for $\mathrm{CP}$ and in situ rumen CP degradability. Total N concentration was determined using an automated Foss-Kjeldahl apparatus (Fisher Scientific, Pittsburgh, PA), and CP concentration was calculated as $\mathrm{N} \times 6.25$ (AOAC International, 2005). Estimation of the feed rumen CP degradation profiles was determined using the in situ method using 3 Danish Holstein nonlactating cows cannulated at the rumen and duodenum (Hvelplund and Weisbjerg, 2000 ). The procedure complied with the guidelines of Danish Ministry of Justice law number 382 (June 10, 1987) act number 726 (September 9, 1993) concerning experiments with animals and the care of experimental animals. Cows were fed at maintenance twice daily with a diet consisting of $67 \%$ hay and $33 \%$ concentrate on a DM basis. The CP concentration of the diet was always greater than $13.7 \%$ of the DM and comprised at least 3 different protein sources. Polyester (Dacron) mesh bags $(11 \times 8.5 \mathrm{~cm}$ and $38-\mu \mathrm{m}$ pore size, Saatifil PES 38/31, Saatitec S.p.A, Veniano, Italy) containing between 1 and $2 \mathrm{~g}$ of sample DM were presoaked in tap water at $39^{\circ} \mathrm{C}$ for 20 min before incubation in the cows' rumens. Samples were incubated in the rumen ventral sac for $0,2,4,8,16,24,48$, and $96 \mathrm{~h}$. Samples from the 0-h time point were not incubated in the rumen and were used for the estimation of soluble CP (see above). After incubation, bags were washed in a washing machine at $25^{\circ} \mathrm{C}$ without soap or spinning. For forage samples, bags were mixed using a stomacher (Seward, Worthing, UK) with $60 \mathrm{~mL}$ of water and then washed to reduce microbial contamination attached to the feed residue. Thereafter, incubation residues were dried overnight at $100^{\circ} \mathrm{C}$ before analysis of total $\mathrm{N}$ concentrations.

Degradation profile parameters based on in situ incubation were estimated by nonlinear regression according to the equation described by Ørskov and McDonald (1979):

$$
\mathrm{CP} \text { degraded }(t)=\mathrm{CP}_{\mathrm{A}}+\mathrm{CP}_{\mathrm{B}} \times\left(1-e^{-\mathrm{CPc} \times t}\right), \quad[1]
$$


Table 1. Description of the sample set analyzed by Fourier-transform infrared spectroscopy $(\mathrm{n}=663)$; samples are grouped according to botanical or industrial origin

\begin{tabular}{ll}
\hline Botanical origin & Industrial origin \\
\hline Cereal grains $(\mathrm{n}=62)$ & DDGS $(\mathrm{n}=34)$ \\
29 Barley & 28 Corn DDGS \\
12 Wheat & 4 Wheat DDGS \\
7 Rye & 2 Barley DDGS \\
5 Triticale & Oil by-products $(\mathrm{n}=200)$ \\
4 Oat & 112 Rapeseed \\
3 Maize & 42 Soybean \\
2 Grain mix & 25 Sunflower \\
Tropical feeds $(\mathrm{n}=9)$ & 12 Cottonseed \\
Maize silage $(\mathrm{n}=12)$ & 2 Soypass \\
10 Maize silage & 2 Treated soybean meal \\
2 Maize silage with pulp & 4 Others \\
Grass-clover forage $(\mathrm{n}=76)$ & Protein products $(\mathrm{n}=16)$ \\
29 Grass-clover forage & 7 Guar meal \\
16 Grass-clover silage & 4 Malt sprouts \\
11 Grass forage & 3 Brewers grains \\
8 Grass silage & 2 Potato protein \\
7 Artificial-dry grass & Mill by-products $(\mathrm{n}=17)$ \\
4 Clover forage & 7 Maize gluten feed \\
1 Festulolium forage & 3 Maize feed meal \\
Barley-wheat forage $(\mathrm{n}=12)$ & 3 Wheat gluten feed \\
8 Winter wheat silage & 2 Wheat bran \\
4 Barley whole crop silage & 2 Amyfeed \\
Concentrate mix $(\mathrm{n}=127)$ & Soybean hulls $(\mathrm{n}=15)$ \\
Maize forage $(\mathrm{n}=2)$ & \\
\hline 1
\end{tabular}

${ }^{1}$ DDGS $=$ dried distillers grains with solubles.

where $\mathbf{C P}_{\mathbf{A}}$ is the soluble fraction and assumed to be immediately degradable in the rumen, $\mathbf{C P}_{\mathbf{B}}$ is the fraction not soluble but degradable in the rumen, $\mathbf{C P}_{\mathbf{C}}$ is the fractional rate of degradation of fraction $\mathrm{CP}_{\mathrm{B}}$ $(\% / \mathrm{h})$, and $t$ is the time (h). Accordingly, CP effective degradability $\left(\mathbf{C P}_{\mathbf{E D}}\right)$ was calculated for each of the 663 samples by using the following equation:

$$
\mathrm{CP}_{\mathrm{ED}}=\mathrm{CP}_{\mathrm{A}}+\mathrm{CP}_{\mathrm{B}} \times\left[\mathrm{CP}_{\mathrm{C}} /\left(\mathrm{CP}_{\mathrm{C}}+\mathrm{CP}_{\mathrm{K}}\right)\right],
$$

where $\mathrm{CP}_{\mathrm{K}}$ is the fractional $\mathrm{CP}$ outflow rate from the rumen $(\% / \mathrm{h})$, which was considered to be fixed at $5 \% / \mathrm{h}$ in the current study.

Water-soluble CP concentration $\left(\mathbf{C P}_{\mathrm{ws}}\right)$ was determined in duplicate. Milled feed (0.5 g) was soaked in 40 $\mathrm{mL}$ of distilled water and left for $1 \mathrm{~h}$ at $20^{\circ} \mathrm{C}$. Samples were then filtered through an $\mathrm{N}$-free filter paper with retention value of 2 (Whatman AGF 607-90 mm; Frisenette ApS, Knebel, Denmark) and further washed with 4 washes of $40 \mathrm{~mL}$ of distilled water. The filter paper with residue was then dried at $100^{\circ} \mathrm{C}$ overnight, weighed, and analyzed for $\mathrm{N}$ residue using the Kjeldahl procedure.

Total-tract CP digestibility ( $\left.\mathbf{C P}_{\text {TTD }}\right)$ was determined using the rumen in situ bag technique combined with the mobile bag technique (Hvelplund, 1985). Briefly, feed samples $(1 \mathrm{~g}$ of $\mathrm{DM})$ were placed into heat-sealed Dacron bags $(6 \times 6 \mathrm{~cm})$ with small pores $(12 \mu \mathrm{m})$. Two bags per feed were incubated in the rumen of each cow for $16 \mathrm{~h}$, and then the bags were washed in a washing machine as described previously. Digested bags were soaked in $3 \mathrm{mM} \mathrm{HCl}(\mathrm{pH}=2.4)$ for $1 \mathrm{~h}$ and then incubated in HCl-pepsin solution $(0.1 \mathrm{~g} / \mathrm{L}, \mathrm{pH}=2.4)$ at $40^{\circ} \mathrm{C}$ for $2 \mathrm{~h}$ in a shaking water bath. Bags were then inserted in the small intestine through a duodenal cannula, recovered from the feces, and washed in a washing machine as described previously. Finally, bag residues were transferred onto $\mathrm{N}$-free filter papers and $\mathrm{N}$ concentrations were determined as described earlier.

\section{Collection of FTIR Spectra}

Infrared spectra were collected from the dried and ground samples by attenuated total reflectance (ATR) from 4000 to $600 \mathrm{~cm}^{-1}$ using an Equinox 55 FTIR spectrometer (Bruker UK Ltd., Coventry, UK) fitted with a Golden Gate ATR accessory (Specac Ltd., Slough, UK). All spectra were averaged over 64 scans at a resolution of $2 \mathrm{~cm}^{-1}$ and corrected for background absorbance by subtraction of the spectrum of the empty ATR crystal. All samples were analyzed in duplicate and absorbance spectra were converted to text files in Opus software (version 4.2, Bruker UK Ltd.) for subsequent data analysis.

\section{Partial Least Squares Regression}

Spectral data were modeled using partial least squares (PLS) regression based on the SIMPLS algorithms 
using the PLS Toolbox of Matlab (version 7.5.0, Eigenvector Research Inc., Wenatchee, WA). Before calibration, spectra were derivatized to the first or second Savitsky-Golay derivative, normalized, and mean center scaled. Models were developed on a randomly selected subset of spectra (containing between 85 and $89 \%$ of the samples) using a "Venetian blind" cross-validation protocol of 10 data splits. The number of components (latent variables) included in the model was selected to minimize the root mean square error of cross validation (RMSECV) and therefore to avoid model overfitting. Similarly, the derivative power was chosen to minimize the model's error. Outlying data were investigated, and spectra with high Hotelling's $T^{2}, Q$ residuals, and observed values that differed by more than 3 standard deviations with respect to the predicted values were removed from the model. The number of outliers removed represented less than $5 \%$ of the samples analyzed. The fit of the model to the data was given by the determination coefficient $\left(\mathrm{R}^{2}\right)$ and the root mean square error of the calibration (RMSEC). Predictive accuracy was assessed using an independent test set of spectra (11 to $15 \%$ of the samples) that had been excluded from the model construction and measured as the determination coefficient of the prediction $\left(\mathbf{R}_{\mathbf{p}}^{2}\right)$ and by root mean square error of prediction (RMSEP). The ratio of performance to deviation (RPD: ratio of the SD of the original data to RMSEP) and the ratio of the range in the reference (RER: ratio of the SD of the original data to RMSEP) were determined as a measurement of the ability of the model to predict a feed composition value. According to Williams and Sobering (1996), an $\mathrm{RPD}<2$ is considered to not give a relevant prediction; values between 2.0 and 2.5 are considered adequate for qualitative feed evaluation (e.g., high, medium, or low concentration of a particular nutrient) or for screening purposes, values $>2.5$ are regarded as acceptable for quantification (or RER $>10$ ), and values $>3$ indicate that the equation can be used for highly accurate quantitative analysis. Finally, to identify the wavelengths with a high importance in the PLS model, variable importance in projection (VIP) scores were determined.

\section{Developing Feed-Specific PLS Regressions}

The potential advantages of developing particular PLS equations for certain feed types in comparison with universal models were investigated. For sample classification, the underlying structure in the sample FTIR spectra was investigated $(\mathrm{n}=663)$. Duplicate spectra were imported into Matlab (version 2007b, The MathWorks Inc., Natick, MA), averaged, derivatized to the first Savitsky-Golay derivative to smooth baseline noise and improve spectral resolution using a 13-point window, and then mean center normalized (mean = $0, \mathrm{SD}=1)$. Principal component analysis $($ PCA) was conducted to explore differences between the different feeds according to their botanical or industrial origin. Canonical variate analysis (CVA) and multivariate ANOVA were performed using Genstat software (version 10, VSN International Ltd., Hemel Hempstead, UK) to evaluate if differences between feed types were significant.

After the spectrometric differences between feeds had been investigated, we decided to classify the feeds into groups according to their botanical or industrial origin, and finally PLS equations were developed for these groups using the same procedure described above.

\section{RESULTS AND DISCUSSION}

In this paper, we proposed to use FTIR spectroscopy as a high-throughput tool to investigate the nutritional value of feeds. The general approach was to correlate FTIR spectra with feed nutritional value obtained from the samples using multivariate regression methods. This required the use of a large calibration data set to develop a regression model that could be then applied to predict the composition of new samples.

\section{Universal Models to Predict Feed CP Nutritional Value}

The concentrations of $\mathrm{CP}, \mathrm{CP}_{\mathrm{WS}}, \mathrm{CP}_{\mathrm{TTD}}$, and rumen $\mathrm{CP}$ degradation data in each feed type are presented in Table 2. The range in values for all these parameters indicate the broad range of feeds represented in the sample set with different botanical origins, states of maturity, feed processing, and preservation methods. This variation was essential to test the utility of FTIR predictions, calibration, and cross validation. The randomly selected calibration and validations sets similarly covered the whole range for each nutritional component.

Several PLS models were developed using either the entire spectral range $\left(500-6000 \mathrm{~cm}^{-1}\right)$ or the so-called fingerprint region $\left(600-1450 \mathrm{~cm}^{-1}\right)$, using different Savitsky-Golay derivatives (e.g., first, second, and third) and a variety of preprocessing procedures: vector normalization, detrending, standard normal variate, or multiplicative scatter correction. For all parameters studied, we observed that the best prediction model was obtained using the first or second derivative of the full spectral range. Moreover, no substantial improvement in model performance was detected by using additional preprocessing procedures, and therefore all models were developed using vector normalization and mean center scaling of the full spectral range. 
Table 2. Crude protein concentration [mean \pm SD (range), $\%$ of DM] and in situ degradability for different groups of feeds (in $\%$ CP, unless otherwise stated) ${ }^{1}$

\begin{tabular}{|c|c|c|c|c|c|c|c|c|c|}
\hline Item & No. & $\mathrm{CP}$ & $\mathrm{CP}_{\mathrm{ED}}$ & $\mathrm{CP}_{\mathrm{A}}$ & $\mathrm{CP}_{\mathrm{B}}$ & $\mathrm{CP}_{\mathrm{PD}}$ & $\mathrm{CP}_{\mathrm{C}}(\% / \mathrm{h})$ & $\mathrm{CP}_{\mathrm{WS}}$ & $\mathrm{CP}_{\text {TTD }}$ \\
\hline Barley-wheat forage & 12 & $10 \pm 2(7-14)$ & $87 \pm 4(79-93)$ & $84 \pm 5(72-90)$ & $7 \pm 3(5-16)$ & $91 \pm 3(87-95)$ & $6.4 \pm 9.8(2.1-37)$ & $65 \pm 9(48-77)$ & $88 \pm 3(84-92)$ \\
\hline Maize forage & 12 & $10 \pm 1(9-11)$ & $1 \pm 5(73-86)$ & $73 \pm 10(56-82)$ & $18 \pm 9(8-35)$ & $91 \pm 1(88-92)$ & $5.0 \pm 5.1(2.3-21)$ & $48 \pm 9(37-64)$ & $87 \pm 2(85-90)$ \\
\hline Total mixed ration & 19 & $17 \pm 5(11-27)$ & $81 \pm 5(74-91)$ & $59 \pm 11(46-82)$ & $37 \pm 11(15-51)$ & $96 \pm 0(95-97)$ & $7.8 \pm 3.2(4.5-14)$ & $39 \pm 14(23-69)$ & $91 \pm 2(88-94)$ \\
\hline Legume forage & 26 & $18 \pm 3(14-25)$ & $78 \pm 10(59-95)$ & $58 \pm 18(31-92)$ & $34 \pm 17(4-64)$ & $92 \pm 4(79-97)$ & $8.7 \pm 5.0(4.8-24)$ & $33 \pm 22(13-76)$ & $87 \pm 6(65-95)$ \\
\hline Grass-clover forage & 76 & $19 \pm 5(9-31)$ & $77 \pm 10(46-93)$ & $47 \pm 19(17-85)$ & $49 \pm 19(10-76)$ & $96 \pm 3(81-100)$ & $8.9 \pm 4.2(1.9-22)$ & $34 \pm 18(11-74)$ & $89 \pm 5(65-95)$ \\
\hline Soybean hulls & 15 & $13 \pm 1(11-15)$ & $61 \pm 5(54-71)$ & $30 \pm 6(21-42)$ & $65 \pm 7(55-79)$ & $96 \pm 5(85-100)$ & $4.4 \pm 0.7(3.1-5.6)$ & $15 \pm 5(7-23)$ & $77 \pm 4(69-82)$ \\
\hline Beet by-products & 22 & $9 \pm 3(6-18)$ & $71 \pm 15(51-96)$ & $40 \pm 30(8-96)$ & $61 \pm 30(15-92)$ & $98 \pm 2(92-100)$ & $6.4 \pm 2.6(4.0-15)^{\prime}$ & $29 \pm 27(1-72)$ & $84 \pm 5(73-92)$ \\
\hline Cereal grains & 62 & $12 \pm 2(8-18)$ & $77 \pm 9(54-94)$ & $43 \pm 14(22-81)$ & $53 \pm 15(15-78)$ & $96 \pm 4(74-100)$ & $12 \pm 7.2(2.6-37)$ & $13 \pm 6(3-31)$ & $93 \pm 5(79-99)$ \\
\hline Mill by-products & 17 & $18 \pm 4(12-23)$ & $74 \pm 9(52-84)$ & $49 \pm 12(29-70)$ & $46 \pm 14(22-71)$ & $94 \pm 4(89-100)$ & $8.0 \pm 4.8(2.3-18)$ & $27 \pm 11(8-51)$ & $87 \pm 6(73-93)$ \\
\hline Tropical feeds & 9 & $18 \pm 6(13-30)$ & $78 \pm 7(69-92)$ & $60 \pm 12(30-71)$ & $36 \pm 13(24-68)$ & $95 \pm 1(94-98)$ & $7.2 \pm 7.2(2.8-26)$ & $12 \pm 4(7-16)$ & $92 \pm 3(89-96)$ \\
\hline Concentrate mix & 127 & $24 \pm 6(12-38)$ & $70 \pm 10(45-87)$ & $43 \pm 12(5-65)$ & $55 \pm 14(32-100)$ & $98 \pm 3(87-100)$ & $5.7 \pm 2.9(2.1-19)$ & $16 \pm 7(0-37)$ & $92 \pm 3(77-98)$ \\
\hline $\begin{array}{l}\text { Dried distillers } \\
\text { grains with solubles }\end{array}$ & 34 & $31 \pm 3(26-38)$ & $50 \pm 15(33-88)$ & $31 \pm 15(13-76)$ & $56 \pm 21(22-87)$ & $87 \pm 17(52-100)$ & $3.3 \pm 1.9(1.0-10)$ & $13 \pm 6(0-28)$ & $88 \pm 9(62-96)$ \\
\hline Legume seeds & 16 & $31 \pm 8(19-42)$ & $82 \pm 9(64-93)$ & $54 \pm 18(23-80)$ & $45 \pm 19(19-77)$ & $99 \pm 2(93-100)$ & $10 \pm 6.0(4.2-26)$ & $30 \pm 17(11-70)$ & $95 \pm 3(88-99)$ \\
\hline Protein products & 16 & $37 \pm 8(19-47)$ & $66 \pm 12(31-77)$ & $34 \pm 11(7-50)$ & $61 \pm 15(40-93)$ & $95 \pm 7(83-100)$ & $6.3 \pm 2.1(1.8-10)$ & $16 \pm 12(1-41)$ & $92 \pm 6(81-99)$ \\
\hline Oil by-products & 200 & $40 \pm 7(12-55)$ & $63 \pm 14(27-91)$ & $25 \pm 15(1-78)$ & $73 \pm 16(15-99)$ & $98 \pm 3(88-100)$ & $6.9 \pm 4.1(1.1-24)$ & $10 \pm 6(0-44)$ & $92 \pm 4(79-99)$ \\
\hline \multicolumn{10}{|l|}{ Sample sets ${ }^{2}$} \\
\hline $\begin{array}{l}\text { Universal } \\
\text { calibration set }\end{array}$ & 568 & $26 \pm 12(6-55)$ & $70 \pm 14(27-96)$ & $40 \pm 20(1-90)$ & $56 \pm 21(4-99)$ & $96 \pm 5(52-100)$ & $7.3 \pm 4.7(1.0-37)$ & $20 \pm 16(0-77)$ & $91 \pm 6(62-99)$ \\
\hline Universal validation set & 95 & $26 \pm 13(7-54)$ & $68 \pm 15(27-94)$ & $39 \pm 21(2-84)$ & $57 \pm 23(8-98)$ & $96 \pm 7(52-100)$ & $7.2 \pm 5.5(1.5-37)$ & $19 \pm 17(3-72)$ & $90 \pm 7(65-99)$ \\
\hline FOR calibration set & 152 & $16 \pm 5(6-31)$ & $77 \pm 11(46-96)$ & $51 \pm 22(8-96)$ & $44 \pm 24(4-92)$ & $95 \pm 4(79-100)$ & $7.9 \pm 5.0(1.9-37)$ & $35 \pm 21(1-77)$ & $87 \pm 6(65-95)$ \\
\hline FOR validation set & 30 & $15 \pm 5(8-31)$ & $76 \pm 10(55-92)$ & $52 \pm 22(8-90)$ & $42 \pm 23(5-92)$ & $94 \pm 4(85-100)$ & $7.8 \pm 4.5(2.2-33)$ & $35 \pm 21(5-72)$ & $87 \pm 6(65-93)$ \\
\hline ERC calibration set & 180 & $20 \pm 9(8-38)$ & $72 \pm 11(52-94)$ & $44 \pm 13(5-81)$ & $53 \pm 15(15-100)$ & $97 \pm 3(74-100)$ & $7.7 \pm 5.5(2.1-37)$ & $16 \pm 8(0-51)$ & $92 \pm 4(73-99)$ \\
\hline ERC validation set & 35 & $19 \pm 7(9-35)$ & $73 \pm 10(48-90)$ & $46 \pm 14(5-76)$ & $51 \pm 15(18-95)$ & $97 \pm 3(77-100)$ & $7.6 \pm 5.8(2.0-30)$ & $17 \pm 8(3-51)$ & $92 \pm 4(81-97)$ \\
\hline PRC calibration set & 231 & $39 \pm 9(12-55)$ & $62 \pm 15(27-93)$ & $27 \pm 16(1-80)$ & $69 \pm 19(15-99)$ & $96 \pm 7(52-100)$ & $6.6 \pm 4.2(1.0-26)$ & $11 \pm 8(0-70)$ & $91 \pm 7(62-99)$ \\
\hline PRC validation set & 35 & $36 \pm 10(13-52)$ & $64 \pm 14(30-89)$ & $30 \pm 17(4-78)$ & $67 \pm 19(19-96)$ & $96 \pm 9(64-100)$ & $6.7 \pm 3.5(1.1-25)$ & $13 \pm 12(1-69)$ & $91 \pm 4(73-99)$ \\
\hline
\end{tabular}


The CP concentration in the samples ranged from 6 to $55 \%$ of DM. A universal regression model based on a training set of data allowed $\mathrm{CP}$ concentration to be predicted in a test set of data to a high degree of accuracy (Table 3 and Supplemental Figure S1; http:// dx.doi.org/10.3168/jds.2013-7127). This universal model showed a low standard error and a high coefficient of determination $\left(\mathrm{R}_{\mathrm{CV}}^{2}=0.92\right)$. Moreover, $\mathrm{RPD}$ was $>3$, indicating that this equation can be used for quantitative analysis (Williams and Sobering, 1996). Similar accuracy has been described to predict the CP concentration in grass samples using FTIR spectroscopy $\left(\mathrm{R}_{\mathrm{CV}}^{2}=0.93\right.$; Allison et al., 2009a) and in TMR $\left(\mathrm{R}_{\mathrm{CV}}^{2}=0.92\right.$; Mentink et al., 2006) and grass samples using NIRS $\left(\mathrm{R}_{\mathrm{CV}}^{2}=0.98\right.$; Ohlsson et al., 2007). These aforementioned studies had a slightly higher accuracy than ours (standard error of the prediction $\approx 1 \%$ ), but the models were not as universal because they were developed using a less diverse sample set $(\mathrm{n}<250)$, in which only a relatively homogeneous set of samples was included. In a recent paper in which different forages were studied using NIRS, Andueza et al. (2011) reported that the degree of precision to measure $\mathrm{CP}$ concentration using a general equation was similar to that of specific equations for particular forage types. Our findings agree with this observation (see below for more specific models) and indicated that nonforage samples can be included in a universal equation without compromising the model's accuracy.

Although feed CP concentration gives an indication of the amount of $\mathrm{N}$ being supplied to the rumen, it provides little information about the availability of protein to the ruminant, because protein reaching the duodenum comprises feed CP that escapes ruminal degradation in addition to the microbial proteins synthesized in the rumen. Considering the range in complexity of feed proteins, and therefore the potential range in rumen degradation kinetics, a large database is needed to obtain robust calibrations for these particular parameters. However, in view of the difficulty of obtaining in situ degradability data, this study may represent the first attempt to obtain universal equations to predict in situ CP degradability in ruminant feeds using FTIR spectroscopy.

Feed samples used in this experiment varied in their CP degradability values (Table 2) and therefore covered a range relevant to most ruminant feeds. Determination of $\mathrm{CP}_{\mathrm{wS}}$ concentration using a universal model achieved a reasonable degree of accuracy $\left(\mathrm{R}_{\mathrm{CV}}^{2}\right.$ $=0.78)$. This finding indicates that the universal model is adequate to predict $\mathrm{CP}_{\mathrm{WS}}$ for quality screening purposes. However, the utility of universal models to predict CP degradability parameters using FTIR spectra was less successful. In particular, predictions of $\mathrm{CP}_{\mathrm{ED}}$, $\mathrm{CP}_{\mathrm{A}}, \mathrm{CP}_{\mathrm{B}}$, and $\mathrm{CP}_{\mathrm{TTD}}$ were determined with modest success $\left(\mathrm{R}_{\mathrm{CV}}^{2}\right.$ between 0.60 and 0.72$)$, and $\mathrm{CP}_{\mathrm{PD}}$ and $\mathrm{CP}_{\mathrm{C}}$ were poorly predicted $\left(\mathrm{R}_{\mathrm{CV}}^{2}<0.3\right)$. Similar results have been reported using NIRS spectra to predict $\mathrm{CP}_{\mathrm{ED}}$ $\left(\mathrm{R}_{\mathrm{CV}}^{2}\right.$ between 0.64 and 0.78$), \mathrm{CP}_{\mathrm{A}}\left(\mathrm{R}_{\mathrm{CV}}^{2}\right.$ between 0.47 and 0.72), $\mathrm{CP}_{\mathrm{B}}\left(\mathrm{R}_{\mathrm{CV}}^{2}\right.$ between 0.45 and 0.81$)$, and $\mathrm{CP}_{\mathrm{C}}$ $\left(\mathrm{R}_{\mathrm{CV}}^{2}\right.$ between 0.27 and 0.63$)$ in grasses (Ohlsson et al., 2007), meadow herbage (Andres et al., 2005b), and in TMR (Mentink et al., 2006).

The success (or otherwise) in the use of FTIR spectroscopy to predict a given nutritional value (e.g., CP degradability) is often viewed as being solely dependent on the spectroscopic technique. However, successful prediction of a nutrient concentration using FTIR spectroscopy and PLS analysis is a dual function of (1) the capability of FTIR spectroscopy to distinguish

Table 3. Partial least squares universal models developed using Fourier-transform infrared spectroscopy to predict CP concentration (in \% of $\mathrm{DM}$ ) and rumen degradation parameters (in $\%$ of $\mathrm{CP}$, unless otherwise stated) ${ }^{1}$

\begin{tabular}{|c|c|c|c|c|c|c|c|c|c|c|}
\hline Item $^{2}$ & SG & $\mathrm{LV}$ & \multicolumn{2}{|c|}{ Calibration $(\mathrm{n}=568)$} & \multicolumn{2}{|c|}{ Cross validation } & \multicolumn{2}{|c|}{ Prediction $(\mathrm{n}=95)$} & $\mathrm{RPD}$ & RER \\
\hline $\mathrm{CP}$ & 1 & 7 & 0.93 & 3.22 & 0.92 & 3.44 & 0.94 & 3.21 & 4.00 & 15.3 \\
\hline $\mathrm{CP}_{\mathrm{A}}$ & 2 & 8 & 0.77 & 9.30 & 0.72 & 10.23 & 0.69 & 11.5 & 1.97 & 8.3 \\
\hline $\mathrm{CP}_{\mathrm{B}}^{\mathrm{A}}$ & 2 & 8 & 0.76 & 10.29 & 0.70 & 11.45 & 0.67 & 13.23 & 1.91 & 7.2 \\
\hline $\mathrm{CP}_{\mathrm{PD}}^{\mathrm{D}}$ & 2 & 6 & 0.36 & 2.79 & 0.26 & 3.02 & 0.35 & 2.69 & 1.85 & 17.7 \\
\hline $\mathrm{CP}_{\mathrm{TTD}}$ & 2 & 8 & 0.67 & 2.75 & 0.59 & 3.06 & 0.60 & 3.14 & 2.03 & 11.9 \\
\hline
\end{tabular}

${ }^{1}$ Details are given of the Savitsky-Golay (SG) derivative, the number of latent variables (LV) used in the model, the determination coefficients of calibration $\left(\mathrm{R}_{\mathrm{C}}^{2}\right)$, cross validation $\left(\mathrm{R}_{\mathrm{CV}}^{2}\right)$, and prediction $\left(\mathrm{R}_{\mathrm{P}}^{2}\right)$, their respective root mean square errors (RMSEC, RMSECV, and RMSEP), the performance to deviation ratio (RPD), and range in reference ratio (RER).

${ }^{2}$ Feed degradation data were determined in situ considering $5 \% / \mathrm{h}$ of rumen passage rate. $\mathrm{CP}_{\mathrm{ED}}=\mathrm{CP}$ effective degradability; $\mathrm{CP}_{\mathrm{A}}=$ soluble fraction and assumed immediately degradable in the rumen; $\mathrm{CP}_{\mathrm{B}}=$ fraction not soluble but degradable in the rumen; $\mathrm{CP}_{\mathrm{C}}=$ fractional rate of degradation of fraction $\mathrm{CP}_{\mathrm{B}} ; \mathrm{CP}_{\mathrm{WS}}=$ water-soluble $\mathrm{CP}$ concentration determined using filter paper; $\mathrm{CP}_{\mathrm{TTD}}=$ total-tract $\mathrm{CP}$ degradability determined using the mobile bag technique. 
characteristics (specifically organic molecular vibrations) associated with the nutrient in question, and (2) the analytical robustness of the reference laboratory method used, which in this case was the in situ method. To this end, the kinetics of in situ CP degradability is not a defined chemical entity and therefore it must be determined using complex and multi-step laboratory procedures that increase the determination error (Ohlsson et al., 2007). Williams (1987) warned that accurate infrared spectrometric predictions are unlikely when laboratory error is disproportional to the concentration range of the nutrient under investigation. As a result, the difficulty observed in developing an accurate universal model to predict $\mathrm{CP}_{\mathrm{TTD}}$ and some in situ degradation parameters (e.g., $\mathrm{CP}_{\mathrm{C}}$ ) was probably due to the relatively large error in the reference method as a consequence of its complexity (Shenk and Westerhaus, 1994).

The use of the in situ method to determine the CP degradability of samples that differ widely in physical and chemical structure (e.g., forages vs. concentrates) may have led to differential leakage of fine particles out of the Dacron bags. Included in the sample set were forages, grains, protein supplements, and feed byproducts; all these feeds had variable particle sizes, and therefore physical leakage of proteins associated with small particles from in situ bags (mainly from concentrates) could lead to an overestimation of $\mathrm{CP}_{\mathrm{A}}$ (Krämer et al., 2013). Likewise, $\mathrm{CP}_{\mathrm{B}}$ could be misrepresented because it is determined as the net difference between $\mathrm{CP}_{\mathrm{A}}$ and the degradation asymptote. This possible leakage is explained by the physical structure of the sample instead of its intrinsic chemical or molecular bonding properties that are analyzed by FTIR spectroscopy.

To investigate the effects of these analytical limitations, samples were classified according to their FTIR spectra, and PLS models were developed for these particular feed types to determine if the accuracy of predictions could be improved beyond those developed as the universal models.

\section{Classification of Feeds According to Their FTIR Spectra}

Previous studies have demonstrated that multivariate analysis based on FTIR spectra is able to discriminate between varieties of tea (He et al., 2007), forage grasses (Schmidt and Skidmore, 2001; Allison et al., 2009a), and plant parts and plants grown in different years (Allison et al., 2009b). Therefore, multivariate analyses of the FTIR spectra from all 663 feed samples were conducted to classify them.

The raw FTIR spectra are shown in Figure 1A, whereas Figure 1B shows the same data after being subjected to first Savitsky-Golay derivative and vector normalization. By doing this, most of the background noise was removed and samples were more comparable. Principal component analysis of derivatized and normalized data from the entire spectral range (500-4000 $\mathrm{cm}^{-1}$ ) showed that $90 \%$ of the variance was captured in the first 10 components. Multivariate ANOVA of those 10 components showed significant differences between the FTIR profiles of the feed types considered $(P<$ 0.001, Wilk's lambda: 0.001). A more detailed study of those differences (Figure 1C) revealed that CVA of the first 5 components was able to discriminate between forage samples and nonforage samples along canonical axis 1. Similarly, canonical axis 2 split concentrate feeds according to their energy- and protein-yielding properties. This distribution pattern provided the basis for classification of the feed sample set into 3 major groups. The first group comprised different types of forages (FOR), such as barley-wheat whole-crop silages, grass-clover, legume, and maize forages and silage, and included TMR and soybean hulls because of their high proportion of forage and forage-like FTIR spectra, respectively. The second group mainly represented energy-rich concentrates (ERC) such as cereal grains, concentrate mixtures, and mill by-products; tropical feeds were also included in this group. Finally, the third group mainly comprised protein-rich concentrates (PRC) such as legume seeds, oil extraction by-products, dried distillers grains with solubles, and other feeds with a CP concentration $>30 \%$ of DM. Multivariate ANOVA of these 3 main groups indicated clear differences in their FTIR profiles $(P<0.001$, Wilk's lambda: 0.069) when the 10 first PC were analyzed. Similarly, CVA indicating the 95\% CI (Figure 1D) showed FOR, ERC, and PRC grouped separately and most of each group's samples shared similar FTIR spectra within the group but differed between groups. Independent PLS models were thus developed for FOR, ERC, and PRC.

\section{Prediction of CP Nutritional Value in Forages}

Higher coefficients of determination have been previously found when equations to predict $\mathrm{CP}$ concentration were developed using NIRS for families of forages instead of using a single universal equation (Berzaghi et al., 2000). The results of this study agree with this because the RMSEP of the FOR model was 1.02 percentage units lower than was found for the universal model. However, this modest improvement agrees with previous work indicating that subdividing a data set does not necessarily lead to large improvements in model accuracy (Andueza et al., 2011).

Most importantly, parameters that describe the kinetics of $\mathrm{CP}$ utilization in the rumen were satisfac- 
A

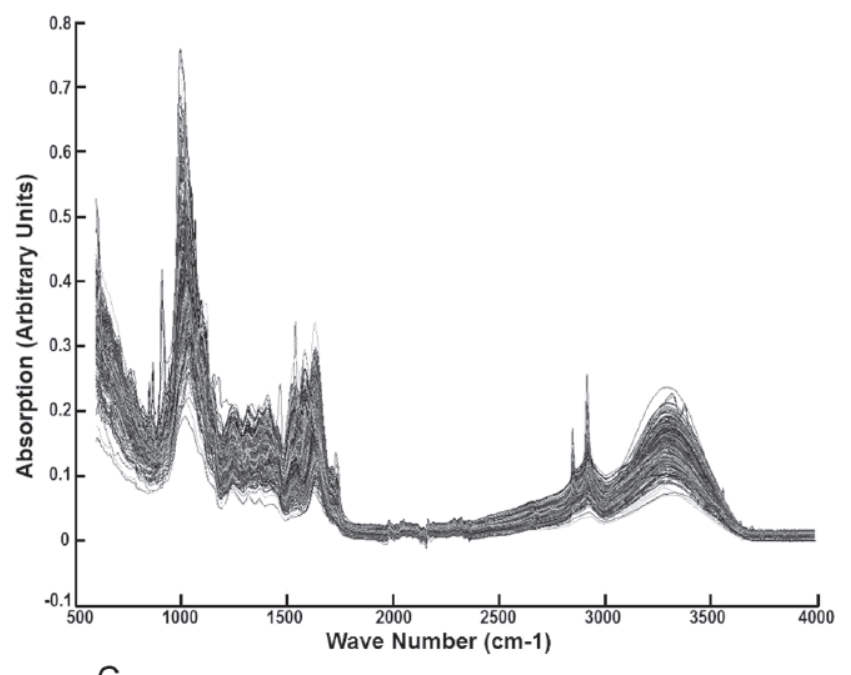

C

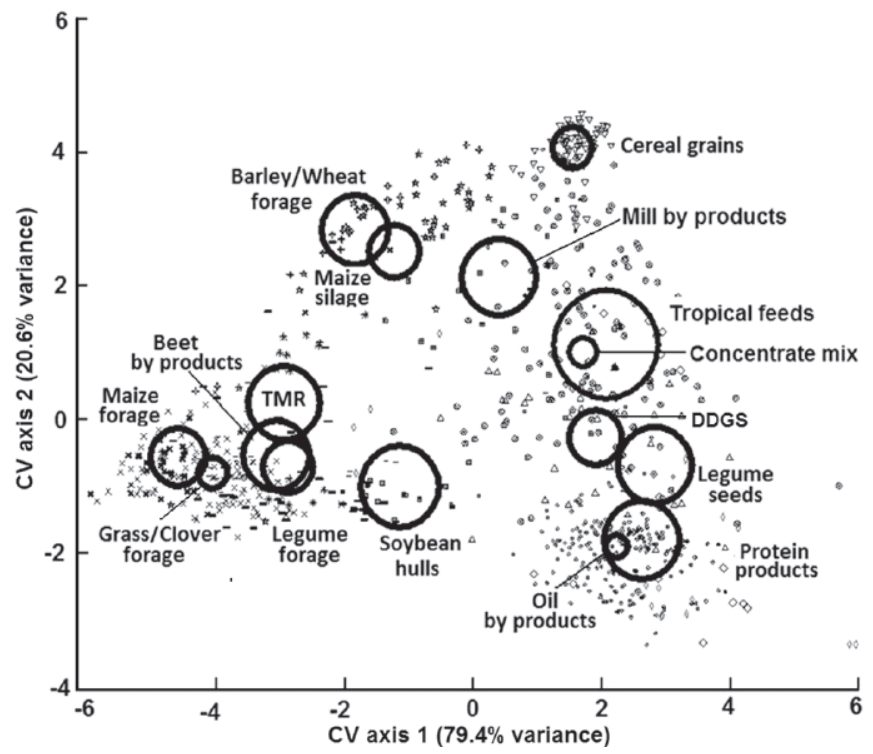

B

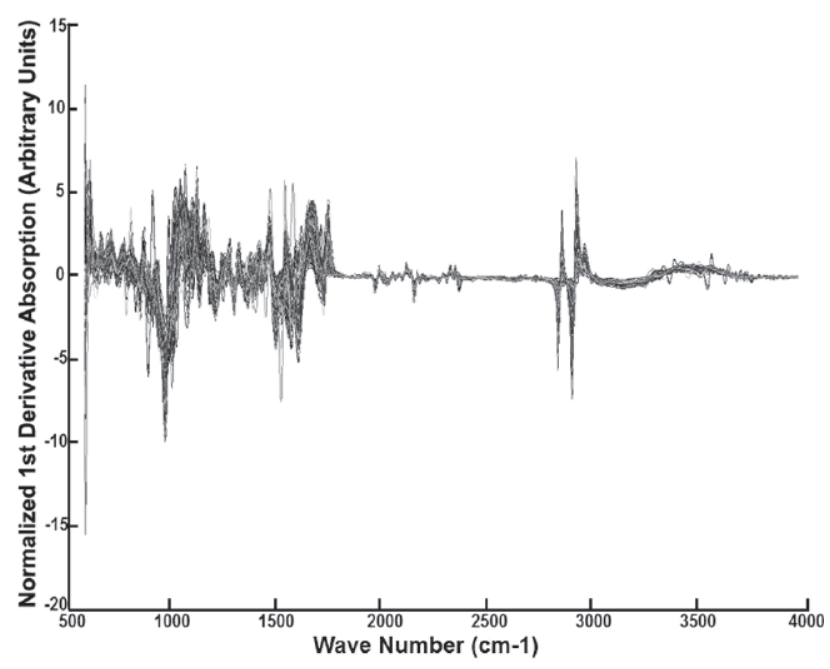

D

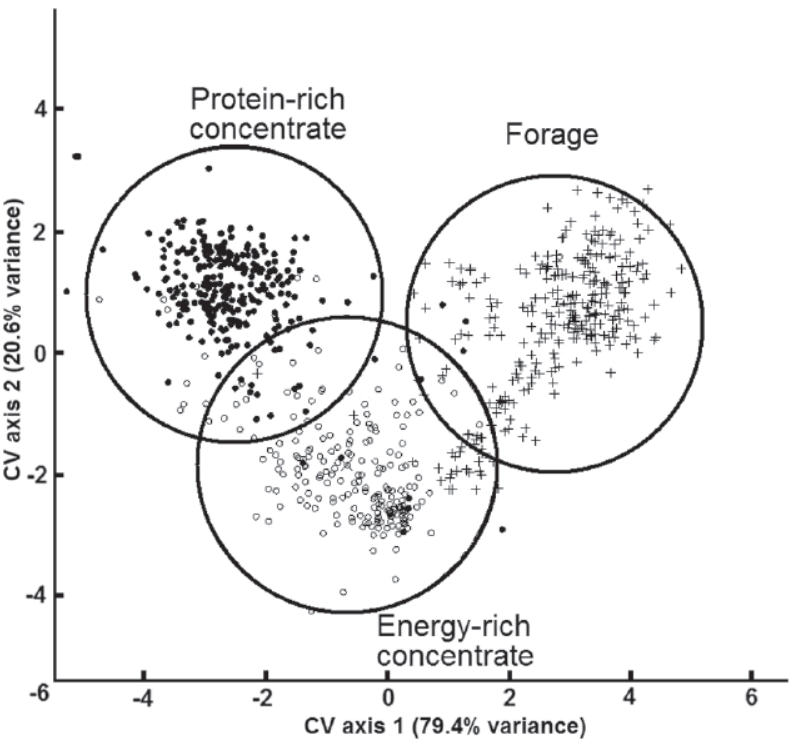

Figure 1. (A) Fourier-transform infrared spectroscopy row spectra of 663 feed samples over the spectral range of 500 to $4000 \mathrm{~cm}^{-1}$; (B) the same spectra after derivatization to the first Savitsky-Golay derivative and vector normalization; canonical variate (CV) analysis score plot of the first 5 principal components according to (C) botanical or industrial origin and (D) 3 main feed types. Large circles indicate the $95 \%$ CI for each sample group. DDGS = dried distillers grains with solubles.

tory predicted in FOR models (Table 4). In particular, concentrations of $\mathrm{CP}_{\mathrm{A}}$ and $\mathrm{CP}_{\mathrm{B}}$ in the feeds were determined with a relatively high accuracy $\left(\mathrm{R}_{\mathrm{CV}}^{2}>\right.$ $0.85, \mathrm{RPD}>2.80)$, yielding predicted standard errors 3.1 and 3.8 percentage units lower for $\mathrm{CP}_{\mathrm{A}}$ and $\mathrm{CP}_{\mathrm{B}}$, respectively, than were found for the universal models (Supplemental Figure S1; http://dx.doi.org/10.3168/ jds.2013-7127). The FOR models also predicted $\mathrm{CP}_{\mathrm{WS}}$ concentration with a similar accuracy to that found in the universal model $\left(\mathrm{R}_{\mathrm{CV}}^{2}=0.83\right)$. As a result, these models can be regarded as being adequate for quantitative purposes of $\mathrm{CP}_{\mathrm{A}}, \mathrm{CP}_{\mathrm{B}}$, and $\mathrm{CP}_{\mathrm{WS}}$ concentrations in FOR feeds. These figures were similar to those observed using NIRS to predict $\mathrm{CP}_{\mathrm{A}}\left(\mathrm{R}^{2}\right.$ between 0.58 and 0.86$), \mathrm{CP}_{\mathrm{B}}\left(\mathrm{R}^{2}\right.$ between 0.45 and 0.81$)$, and $\mathrm{CP}_{\mathrm{WS}}$ concentrations $\left(\mathrm{R}^{2}\right.$ between 0.70 and 0.82$)$ in barley straws (Mathison et al., 1999), meadow forages (Andres et al., 2005b), grass hays (Ohlsson et al., 2007), grass silages (Hoffman et al., 1999), and TMR (Mentink et al., 2006).

Hedqvist and Uden (2006) demonstrated that soluble proteins are not instantly degraded in the rumen and their degradation rates depend on the protein source, tannin content, and wilting time. The latter factor can 
Table 4. Partial least squares models developed using Fourier-transform infrared spectroscopy to predict CP concentration (in \% of DM) and rumen degradation parameters of forages (in \% of CP, unless otherwise stated) ${ }^{1}$

\begin{tabular}{|c|c|c|c|c|c|c|c|c|c|c|}
\hline Item $^{2}$ & SG & LV & \multicolumn{2}{|c|}{ Calibration $(\mathrm{n}=152)$} & \multicolumn{2}{|c|}{ Cross validation } & \multicolumn{2}{|c|}{ Prediction $(\mathrm{n}=30)$} & RPD & RER \\
\hline $\mathrm{CP}$ & 1 & 8 & 0.91 & 1.52 & 0.86 & 1.95 & 0.82 & 2.19 & 2.75 & 11.8 \\
\hline $\mathrm{CP}_{\mathrm{A}}$ & 2 & 8 & 0.94 & 5.52 & 0.88 & 7.82 & 0.87 & 8.38 & 2.89 & 11.3 \\
\hline $\mathrm{CP}_{\mathrm{B}}$ & 2 & 8 & 0.93 & 6.26 & 0.87 & 8.59 & 0.85 & 9.47 & 2.80 & 10.3 \\
\hline $\mathrm{CP}_{\mathrm{PD}}$ & 2 & 7 & 0.79 & 1.59 & 0.63 & 2.11 & 0.56 & 2.19 & 2.49 & 9.8 \\
\hline $\mathrm{CP}_{\text {TTD }}$ & 1 & 8 & 0.80 & 2.31 & 0.77 & 3.01 & 0.77 & 2.61 & 2.32 & 11.7 \\
\hline
\end{tabular}

${ }^{1}$ Details are given of the Savitsky-Golay ( $\mathrm{SG}$ ) derivative, the number of latent variables (LV) used in the model, the determination coefficients of calibration $\left(\mathrm{R}_{\mathrm{C}}^{2}\right)$, cross validation $\left(\mathrm{R}_{\mathrm{CV}}^{2}\right)$, and prediction $\left(\mathrm{R}_{\mathrm{P}}^{2}\right)$, their respective root mean square errors (RMSEC, RMSECV, and RMSEP), the performance to deviation ratio (RPD), and range in reference ratio (RER).

${ }^{2}$ Feed degradation data were determined in situ considering $5 \% / \mathrm{h}$ of rumen passage rate. $\mathrm{CP}_{\mathrm{ED}}=\mathrm{CP}$ effective degradability; $\mathrm{CP}_{\mathrm{A}}=$ soluble fraction and assumed immediately degradable in the rumen; $\mathrm{CP}_{\mathrm{B}}=$ fraction not soluble but degradable in the rumen; $\mathrm{CP}_{\mathrm{C}}=\mathrm{fractional}_{\mathrm{rate}}$ of degradation of fraction $\mathrm{CP}_{\mathrm{B}} ; \mathrm{CP}_{\mathrm{WS}}=$ water-soluble $\mathrm{CP}$ concentration determined using filter paper; $\mathrm{CP}_{\mathrm{TTD}}=$ total-tract $\mathrm{CP}$ degradability determined using the mobile bag technique.

modify the activity of antiproteolytic enzymes (Lee et al., 2013); as a result, they suggested that the in situ method, which assumes complete and instant degradation of soluble proteins, should not be used for feeds with high soluble protein concentrations. To this end, the ability of FTIR spectroscopy to simultaneously quantify $\mathrm{CP}_{\mathrm{WS}}, \mathrm{CP}_{\mathrm{A}}$, and $\mathrm{CP}_{\mathrm{B}}$ in many of the forages commonly fed to ruminants represents a step forward for feed evaluation.

In addition, moderate accuracy in the prediction of $\mathrm{CP}_{\mathrm{ED}}$ and $\mathrm{CP}_{\mathrm{TTD}}$ was observed for FOR samples $\left(\mathrm{R}_{\mathrm{CV}}^{2}\right.$ $<0.8$ ). These figures were slightly more accurate than those observed in the universal models and had similar coefficients of determination as described in narrower models $\left(\mathrm{R}^{2}\right.$ between 0.64 and 0.79 for $\mathrm{CP}_{\mathrm{ED}}$ ) for barley straws (Mathison et al., 1999) and meadow grasses using NIRS (Andres et al., 2005b). As a result, although our models cannot be considered accurate enough for quantitative analysis, they could be adequate for quality screening purposes of most FOR samples according to their $\mathrm{CP}_{\mathrm{ED}}$ and $\mathrm{CP}_{\mathrm{TTD}}$.

The $\mathrm{CP}_{\mathrm{C}}$ in FOR samples was poorly predicted. Because $\mathrm{CP}_{\mathrm{C}}$ is determined using a 2-stage assay, the possibility exists of greater laboratory error than is found in simpler procedures such as CP determination. Even so, these predictions were better than previously described for TMR and grass forages using NIRS $\left(\mathrm{R}_{\mathrm{CV}}^{2}\right.$ $=0.27$ to 0.63; Mentink et al., 2006; Ohlsson et al., 2007) but slightly worse than described for legume and grass silages $\left(\mathrm{R}^{2}>0.87\right.$; Hoffman et al., 1999). These discrepancies in the accuracy of the models to predict degradation rate may rely on the different samples considered (e.g., a more heterogeneous sample set for TMR than for silages).
These findings indicate that FTIR spectroscopy can be used as an inexpensive high-throughput technique to evaluate forage $\mathrm{CP}$ concentrations. This technique also provides some broad information about the magnitude and location (rumen vs. intestine) in which the forage's $\mathrm{CP}$ is degraded within the ruminant gastrointestinal tract.

\section{Prediction of CP Nutritional Value in Concentrates}

A total of 481 concentrate feeds were investigated in the present study (i.e., cereal grains, legume seeds, concentrate mix, protein products, DGGS, tropical feeds, and mill and oil by-products). They varied widely in their physical and chemical composition and, based on the initial CVA analysis, concentrates were classified in 2 groups (ERC and PRC) to investigate the ability of FTIR spectroscopy to predict their nutritional value within more comparable data sets.

In general, the use of PLS models based on FTIR spectroscopy to predict $\mathrm{CP}$ degradability, $\mathrm{CP}_{\mathrm{WS}}$, and $\mathrm{CP}_{\text {TTD }}$ values in ERC (Table 5) was less successful than observed in FOR or in the whole sample data set. With the exception of CP concentration, which could be predicted accurately, as has been found previously for poultry feeds using NIR (Valdes et al., 1985), the other parameters studied were poorly predicted $\left(\mathrm{R}_{\mathrm{CV}}^{2}\right.$ $<0.55)$. Three major factors might explain the lack of success in the prediction of CP degradabilities in ERC. First, most of the ERC samples were made up of a mixture of different ingredients with variable degradation rates. This diversity in protein origin seems to exert a negative effect on the accuracy of the predictions (Williams and Starkey, 1980). Second, as discussed earlier, 
the physical leakage of fine material out of the rumen incubation bags substantially increases the error of the in situ method when concentrate feeds are analyzed. Third, another limitation of the in situ method is that all degradation parameters are interrelated; therefore, possible errors in one parameter modify all degradation fractions that are subsequently calculated. As a consequence of that, standardization of the in situ procedures is essential to achieve appropriate estimations of the feed nutritional value (Hvelplund et al., 2003). Despite these methodological limitations and the importance of ERC in the diets of certain ruminant livestock (e.g., dairy and feedlot cattle), the potential negative implications of the relatively inaccurate prediction of their CP degradation kinetics may be offset by the generally low and relatively constant $\mathrm{CP}$ concentrations observed in these feeds.

Concentrates classified as PRC varied widely in their $\mathrm{CP}$ concentration (from 12 to $55 \%$ of DM). This parameter was accurately predicted by FTIR spectroscopy with an expected standard error lower than that observed in the universal model (Table 6). Similarly, substantial improvements in the prediction of $\mathrm{CP}_{\mathrm{ED}}, \mathrm{CP}_{\mathrm{A}}$, and $\mathrm{CP}_{\mathrm{B}}$ were observed in PRC models compared with the universal models. In particular, RMSEP decreased 4 percentage units for $\mathrm{CP}_{\mathrm{A}}$ and $\mathrm{CP}_{\mathrm{B}}$ and 2 percentage units for $\mathrm{CP}_{\mathrm{ED}}$ compared with the universal models; moreover, all 3 models showed similar coefficient of determinations $\left(\mathrm{R}_{\mathrm{CV}}^{2} \approx 0.74\right)$. In line with this, $\mathrm{CP}_{\mathrm{WS}}$ and $\mathrm{CP}_{\mathrm{TTD}}$ were better predicted in PRC models than in universal models. The figures for PRC were similar to those observed in FOR models for $\mathrm{CP}_{\mathrm{TTD}}$, but had a lower coefficient of determination for $\mathrm{CP}_{\mathrm{WS}}$. $\mathrm{Up}$ to two-thirds of the PRC were oil by-products; therefore, the $\mathrm{CP}$ solubility and rumen degradation pattern of these feeds may be highly influenced by the industrial treatments applied during the oil extraction procedures (e.g., solvents and high temperatures and pressures), as well as by the proportional accumulation of certain active compounds (e.g., tannins, saponins, and proteinbinding enzymes) able to bind to and precipitate proteins and amino acids. These factors seem to modify the $\mathrm{CP}$ degradation pattern, leading to a decrease in the FTIR predictions. Despite this, models developed for PRC would be accurate enough to conduct feed screening according to concentrations of $\mathrm{CP}_{\mathrm{WS}}, \mathrm{CP}_{\mathrm{TTD}}$, $\mathrm{CP}_{\mathrm{A}}, \mathrm{CP}_{\mathrm{B}}$, and $\mathrm{CP}_{\mathrm{ED}}$ in the feeds.

In spite of the poor results found for the ERC-only models, our findings indicated that certain improvements in the prediction of $\mathrm{CP}$ concentration and rumen $\mathrm{CP}$ degradation can be achieved for PRC feeds compared with the whole sample data set. This represents a step forward in ruminant nutrition because it allows an inexpensive and quick evaluation of the rumen degradation pattern for the most common protein sources used in ruminant nutrition.

\section{VIP Scores}

In general, spectroscopy is based on the fact that the spectrum of a sample after excitation with a laser is directly related to its chemical composition. Therefore, a VIP score analysis was performed to identify the most important wavenumbers in the more promising PLS models (Table 7). This analysis indicated that FTIR models developed to describe feed CP concentration had prominent VIP scores corresponding with known areas of $\mathrm{N}$ absorption (Barth and Zscherp, 2002). Most of these wavenumbers were within the fingerprint region (600 to $1450 \mathrm{~cm}^{-1}$ ), and although the complexity

Table 5. Partial least squares models developed using Fourier-transform infrared spectroscopy to predict CP concentration (in \% DM) and rumen degradation parameters of energy-rich concentrates (in \% CP, unless stated) ${ }^{1}$

\begin{tabular}{|c|c|c|c|c|c|c|c|c|c|c|}
\hline Item $^{2}$ & SG & LV & \multicolumn{2}{|c|}{ Calibration $(\mathrm{n}=180)$} & \multicolumn{2}{|c|}{ Cross validation } & \multicolumn{2}{|c|}{ Prediction $(\mathrm{n}=35)$} & $\mathrm{RPD}$ & RER \\
\hline $\mathrm{CP}$ & 2 & 7 & 0.94 & 1.72 & 0.87 & 2.43 & 0.88 & 2.51 & 3.50 & 15.6 \\
\hline $\mathrm{CP}_{\mathrm{A}}$ & 2 & 8 & 0.70 & 6.60 & 0.47 & 9.11 & 0.54 & 7.31 & 1.85 & 10.4 \\
\hline $\mathrm{CP}_{\mathrm{B}}$ & 2 & 7 & 0.70 & 7.29 & 0.54 & 9.17 & 0.53 & 7.87 & 1.91 & 10.8 \\
\hline $\mathrm{CP}_{\mathrm{PD}}$ & 2 & 6 & 0.60 & 1.84 & 0.33 & 2.43 & 0.30 & 2.47 & 1.41 & 10.7 \\
\hline $\mathrm{CP}_{\mathrm{TTD}}$ & 2 & 5 & 0.61 & 1.77 & 0.46 & 2.08 & 0.64 & 2.01 & 2.32 & 14.7 \\
\hline
\end{tabular}

${ }^{1}$ Details are given of the Savitsky-Golay (SG) derivative, the number of latent variables (LV) used in the model, the determination coefficients of calibration $\left(\mathrm{R}_{\mathrm{C}}^{2}\right)$, cross validation $\left(\mathrm{R}_{\mathrm{CV}}^{2}\right)$, and prediction $\left(\mathrm{R}_{\mathrm{P}}^{2}\right)$, their respective root mean square errors (RMSEC, RMSECV, and RMSEP), the performance to deviation ratio (RPD), and range in reference ratio (RER).

${ }^{2}$ Feed degradation data were determined in situ considering $5 \% / \mathrm{h}$ of rumen passage rate. $\mathrm{CP}_{\mathrm{ED}}=\mathrm{CP}$ effective degradability; $\mathrm{CP}_{\mathrm{A}}=$ soluble fraction and assumed immediately degradable in the rumen; $\mathrm{CP}_{\mathrm{B}}=$ fraction not soluble but degradable in the rumen; $\mathrm{CP}_{\mathrm{C}}=$ fractional rate of degradation of fraction $\mathrm{CP}_{\mathrm{B}} ; \mathrm{CP}_{\mathrm{WS}}=$ water-soluble $\mathrm{CP}$ concentration determined using filter paper; $\mathrm{CP}_{\mathrm{TTD}}=$ total-tract $\mathrm{CP}$ degradability determined using the mobile bag technique. 
Table 6. Partial least squares models developed using Fourier-transform infrared spectroscopy to predict CP concentration (in \% of DM) and rumen degradation parameters of protein-rich concentrates (in \% of $\mathrm{CP}$, unless otherwise stated) ${ }^{1}$

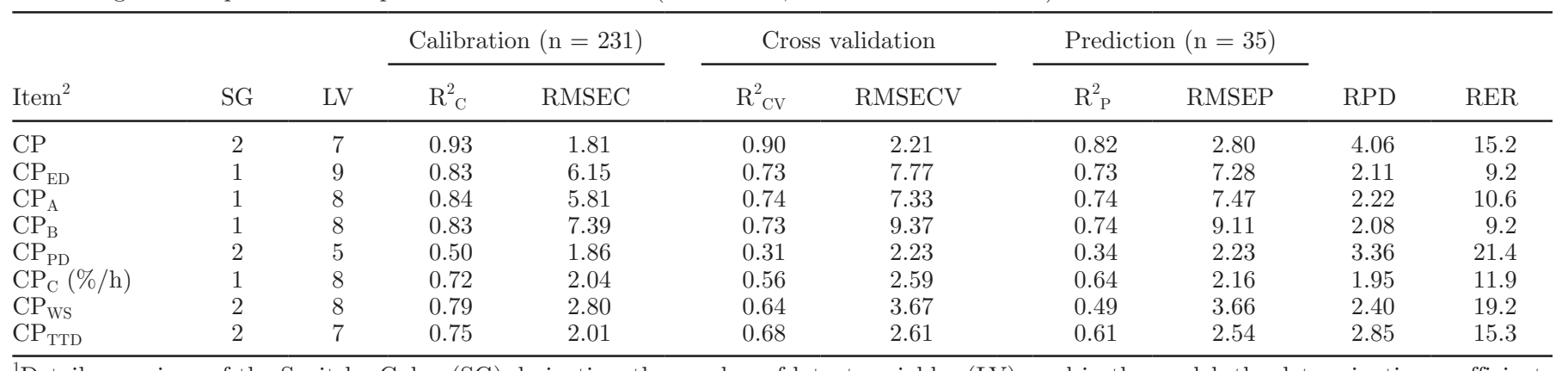

${ }^{1}$ Details are given of the Savitsky-Golay (SG) derivative, the number of latent variables (LV) used in the model, the determination coefficients of calibration $\left(\mathrm{R}_{\mathrm{C}}^{2}\right)$, cross validation $\left(\mathrm{R}_{\mathrm{CV}}^{2}\right)$, and prediction $\left(\mathrm{R}_{\mathrm{P}}^{2}\right)$, their respective root mean square errors (RMSEC, RMSECV, and RMSEP), the performance to deviation ratio (RPD), and range in reference ratio (RER).

${ }^{2}$ Feed degradation data were determined in situ considering $5 \% / \mathrm{h}$ of rumen passage rate. $\mathrm{CP}_{\mathrm{ED}}=\mathrm{CP}$ effective degradability; $\mathrm{CP}_{\mathrm{A}}=$ soluble fraction and assumed immediately degradable in the rumen; $\mathrm{CP}_{\mathrm{B}}=$ fraction not soluble but degradable in the rumen; $\mathrm{CP}_{\mathrm{C}}=\mathrm{fractional}_{\mathrm{rate}}$ of degradation of fraction $\mathrm{CP}_{\mathrm{B}}$; $\mathrm{CP}_{\mathrm{WS}}=$ water-soluble $\mathrm{CP}$ concentration determined using filter paper; $\mathrm{CP}_{\mathrm{TTD}}=$ total-tract $\mathrm{CP}$ degradability determined using the mobile bag technique.

of infrared spectra in this region makes it difficult to assign the absorption, these vibrations are likely to be associated with $\mathrm{C}-\mathrm{N}$ bond stretching. Specifically, most of our models showed prominent VIP scores in the region in which the amine $\mathrm{C}-\mathrm{N}$ stretching happens (1000 to $1250 \mathrm{~cm}^{-1}$; Barth and Zscherp, 2002).

On the other hand, some important vibrations were observed in the group-frequency region (1450 to 4000 $\mathrm{cm}^{-1}$ ), which is usually due to stretching vibrations of diatomic units. Within this region, vibrations compatible with $\mathrm{C}=\mathrm{N}$ stretching (1600 to $1700 \mathrm{~cm}^{-1}$ ), N-H stretching (2775 to $3600 \mathrm{~cm}^{-1}$ ), amine $\mathrm{NH}_{2}$ scissoring (1150 to $1650 \mathrm{~cm}^{-1}$ ), and amide NH bending (1500 to $1560 \mathrm{~cm}^{-1}$ ) were observed (Barth and Zscherp, 2002). Finally, other VIP scores were explained by the models' contribution of non-N-containing bonds due to the presence of carbon skeletons in organic N-containing compounds. To this end, the universal model to predict $\mathrm{CP}$ concentration showed the lowest number of increased VIP scores (i.e., 6), suggesting a direct correlation between the presence of certain $\mathrm{N}$-containing molecules and the feed protein content. Therefore, accurate prediction of $\mathrm{CP}$ concentration using FTIR spectroscopy relies on the high repeatability of the reference method and the presence in the sample of $\mathrm{N}$-containing molecules able to be detected by FTIR spectroscopy (Mentink et al., 2006).

In terms of CP fractions and degradation parameters, PLS models generated a high number of prominent VIP scores $(>11)$. This might be due to the complex nature of the molecules that determine $\mathrm{CP}$ solubility and digestibility and to the interactions of proteins with active secondary compounds (e.g., tannins, saponins, oils, and enzymes) and nonactive components (e.g., fiber) that can modify the rumen degradation pattern and subsequently the protein nutritional value (Hedqvist and Uden, 2006).

One example of these interactions was observed in the models used to predict $\mathrm{CP}_{\mathrm{A}}, \mathrm{CP}_{\mathrm{B}}$, and $\mathrm{CP}_{\mathrm{ED}}$ in FOR samples. These models showed prominent VIP scores at 932, 990, 1042, 1080, 1063, and $1124 \mathrm{~cm}^{-1}$, which are suggestive of $\mathrm{C}-\mathrm{O}-\mathrm{C}$ stretching in lignin (1060 to $\left.1150 \mathrm{~cm}^{-1}\right)$ and cellulose $\left(1050\right.$ to $\left.1130 \mathrm{~cm}^{-1}\right)$, and $\mathrm{C}-\mathrm{O}$ stretching in starch $\left(980\right.$ to $\left.1150 \mathrm{~cm}^{-1}\right)$ and monosaccharides (800 to $1000 \mathrm{~cm}^{-1}$; Lammers et al., 2009). These findings indicate that the presence of high levels of fiber in the diet can delay CP degradation in the rumen, perhaps because fiber inhibits microbial access to the feed proteins.

Similarly, models to predict $\mathrm{CP}_{\mathrm{A}}, \mathrm{CP}_{\mathrm{B}}$, and $\mathrm{CP}_{\mathrm{ED}} \mathrm{PRC}$ feeds showed a very prominent VIP score $(>30)$ at 1628 $\mathrm{cm}^{-1}$, which is associated with amide $\mathrm{C}=\mathrm{O}$ stretching and $\mathrm{N}-\mathrm{H}$ bending, and with pectin concentration (1605 to $1630 \mathrm{~cm}^{-1}$; Lammers et al., 2009). Pectins are highly degradable polysaccharides that make up a substantial proportion of the plant cell wall (about 30\%); however, hydrated pectin forms gels that could decrease, to some extent, CP degradation within the nylon bag.

Therefore, our findings suggest that FTIR spectroscopy demonstrates a direct relationship between feed protein feeding values and the vibrations of certain feed component attributes. In particular, the estimation of the CP degradation parameters using FTIR spectroscopy is mainly determined by the $\mathrm{CP}$ concentration (indicated by the $\mathrm{C}-\mathrm{N}$ stretching). This feed's $\mathrm{CP}$ degradation pattern can also be affected by the ratio of structural to nonstructural carbohydrates and by the presence of certain compounds that can modify $\mathrm{CP}$ solubility in the rumen. However, this observation must be taken with caution because FTIR spectroscopy is 
Table 7. Variable importance in projection (VIP) scores of different models showing the wave numbers most important for the prediction of CP concentration and rumen degradation parameters using Fourier-transform infrared spectroscopy

\begin{tabular}{|c|c|c|c|c|c|c|c|c|c|c|c|c|c|c|c|c|c|c|}
\hline \multicolumn{2}{|c|}{ Vibrations } & \multirow{2}{*}{$\begin{array}{l}\text { Wave } \\
\left(\mathrm{cm}^{-1}\right)\end{array}$} & \multicolumn{2}{|c|}{ Universal } & \multicolumn{6}{|c|}{ FOR } & \multicolumn{2}{|c|}{ ERC } & \multicolumn{6}{|c|}{ PRC } \\
\hline Bending & Stretching & & $\mathrm{CP}$ & $\mathrm{CP}_{\mathrm{WS}}$ & $\mathrm{CP}$ & $\mathrm{CP}_{\mathrm{ED}}$ & $\mathrm{CP}_{\mathrm{A}}$ & $\mathrm{CP}_{\mathrm{B}}$ & $\mathrm{CP}_{\mathrm{WS}}$ & $\mathrm{CP}_{\text {TTD }}$ & $\mathrm{CP}$ & $\mathrm{CP}_{\mathrm{ED}}$ & $\mathrm{CP}$ & $\mathrm{CP}_{\mathrm{ED}}$ & $\mathrm{CP}_{\mathrm{A}}$ & $\mathrm{CP}_{\mathrm{B}}$ & $\mathrm{CP}_{\mathrm{WS}}$ & $\mathrm{CP}_{\mathrm{TTD}}$ \\
\hline \multirow[t]{3}{*}{$\mathrm{Amine}^{2}$} & \multirow{7}{*}{$\mathrm{C}-\mathrm{N}$} & 617 & & 5 & & & & & & & & & 12 & 8 & & 8 & 10 & 6 \\
\hline & & 631 & & & & & & & & & & & 6 & 6 & & 7 & & \\
\hline & & 897 & & & & & & & & 6 & 9 & & 5 & & & & & \\
\hline \multirow{16}{*}{ Multiple } & & 932 & & & 6 & 16 & 15 & 14 & 14 & 16 & & & & & & & & 7 \\
\hline & & 955 & & & & 7 & & 9 & 7 & & 7 & & & & & & & \\
\hline & & 978 & 29 & & 24 & & 8 & 9 & 6 & 10 & 11 & 7 & & 8 & 7 & & & \\
\hline & & 990 & & 8 & & 17 & 29 & 30 & 23 & & 31 & 10 & 11 & & & & 8 & 9 \\
\hline & & 1009 & & & 11 & 7 & 7 & 7 & 8 & 12 & 17 & & & 14 & & & & \\
\hline & & 1030 & 26 & 14 & 17 & & & & & & 8 & 21 & & & & & & \\
\hline & & 1042 & & & 10 & 16 & 11 & 11 & 11 & 11 & & 17 & & & & 12 & 17 & \\
\hline & & 1063 & & & & 23 & 45 & 46 & 42 & & 26 & 9 & & & & & 13 & \\
\hline & Amines & 1080 & & & & 14 & 24 & 25 & 20 & 7 & 26 & & & 10 & & & 7 & 7 \\
\hline & $\mathrm{C}-\mathrm{N}$ & 1097 & & & & 7 & 10 & 9 & 11 & & 6 & & 12 & & 7 & 7 & 6 & 15 \\
\hline & & 1124 & & 14 & & 30 & 38 & 35 & 41 & & & 15 & 9 & & & & & 6 \\
\hline & & 1140 & & & & 7 & 7 & 7 & 9 & 7 & & & 16 & 8 & & 5 & & \\
\hline & & 1150 & & 10 & & & & & & & 10 & 8 & 6 & & & 7 & & \\
\hline & 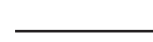 & 1184 & & & 8 & & & & & & & & 15 & 6 & & & & 14 \\
\hline & $\mathrm{C}-\mathrm{N}$ & 1395 & & & & & & & & & & & 6 & & & & 7 & 6 \\
\hline & $c=10$ & 1481 & 12 & 8 & & & 7 & 7 & 7 & & 6 & & 8 & 6 & & 6 & 8 & 6 \\
\hline \multirow{11}{*}{$\begin{array}{l}\text { Amine } \\
\text { and amide }\end{array}$} & & 1537 & & 14 & & & & & 5 & & 7 & & 17 & & & & 11 & 9 \\
\hline & & 1551 & 8 & & & & & & & & & 13 & 6 & 11 & 8 & 7 & 22 & \\
\hline & \multirow{6}{*}{$\mathrm{C}=\mathrm{N}$} & 1582 & & 3 & & 19 & 15 & 13 & 22 & 6 & & 6 & 12 & 9 & & & & 5 \\
\hline & & 1607 & & & & & & & & 17 & & & & & 8 & 5 & & \\
\hline & & 1618 & 12 & 12 & 6 & 6 & & & & & 11 & 21 & & & & & 42 & 7 \\
\hline & & 1628 & & & 5 & & & & & & & 12 & 18 & 39 & 46 & 30 & 14 & 19 \\
\hline & & 1707 & 10 & 5 & & & 5 & 5 & 6 & & 6 & 14 & 15 & 5 & 6 & 7 & & 19 \\
\hline & & 1745 & & 10 & & & & & & & & 38 & 17 & & 6 & 6 & 6 & 15 \\
\hline & \multirow{3}{*}{$\mathrm{N}-\mathrm{H}$} & 2853 & & & 5 & 7 & & & & & 9 & & 14 & & 5 & 5 & & 10 \\
\hline & & 2915 & & & 7 & 9 & & & & & 11 & & 10 & & 6 & 5 & & 9 \\
\hline & & 2932 & & & 10 & & & & & 5 & & 8 & & & 7 & 6 & & \\
\hline
\end{tabular}

${ }^{1}$ Only models with $\mathrm{R}^{2}>0.7$ and VIP $>5$ are shown. Table cells are shaded according to the VIP value; that is, the values in bold have the highest VIP; values in italics are intermediate; and the values in roman (normal) font are lowest. Feed degradation data were determined in situ considering $5 \% / \mathrm{h}$ of rumen passage rate. $\mathrm{CP} \mathrm{ED}_{\mathrm{B}}=\mathrm{CP}$ effective degradability; $\mathrm{CP}_{\mathrm{A}}=$ soluble fraction and assumed immediately degradable in the rumen; $\mathrm{CP}_{\mathrm{B}}=$ fraction not soluble but degradable in the rumen; $\mathrm{CP}_{\mathrm{C}}=$ fractional rate of degradation of fraction $\mathrm{CP}_{\mathrm{B}} ; \mathrm{CP}_{\mathrm{WS}}=$ water-soluble $\mathrm{CP}$ concentration determined using filter paper; $\mathrm{CP}_{\mathrm{TTD}}=$ total-tract $\mathrm{CP}$ degradability determined using the mobile bag technique; $\mathrm{FOR}=$ forages; $\mathrm{ERC}=$ energy-rich concentrates; $\mathrm{PRC}=$ protein-rich concentrates.

${ }^{2} \mathrm{Amine} \mathrm{NH}_{2}$ and $\mathrm{NH}$ wagging vibrations.

${ }^{3} \mathrm{Amine} \mathrm{NH}_{2}$ scissoring and amide $\mathrm{NH}$ bending vibrations. 
not sensitive enough to assign a molecule name to those increased VIP scores (Chauvin and Field, 1992).

\section{CONCLUSIONS}

The use of predictive PLS models based on the FTIR spectra of feed samples is a promising method to estimate feed $\mathrm{CP}$ concentration and rumen $\mathrm{CP}$ degradation patterns. The analysis of a large set of samples by FTIR spectroscopy allowed the development of universal models able to satisfactorily determine the $\mathrm{CP}$ concentration in many feeds used for ruminants and to provide information about their biological nutritional value (i.e., solubility and degradability). Fourier-transform infrared spectroscopy was particularly accurate in predicting the $\mathrm{CP}$ concentration in forages and the kinetics of $\mathrm{CP}$ degradation into the rumen. However, models developed to evaluate concentrates had a lower accuracy and only in protein-rich concentrates was it possible to estimate the rumen $\mathrm{CP}$ degradation pattern reasonably well. Most of the FTIR predictions showed similar accuracies to methods using NIRS; therefore, FTIR spectroscopy should be considered as a low-cost alternative in the feed evaluation industry. Further studies are required to ascertain the usefulness of FTIR spectroscopy in predicting other nutrient concentrations (e.g., fibers) and their degradabilities.

\section{ACKNOWLEDGMENTS}

This study was supported by Framework 7 program from the EU "Innovative and practical management approaches to reduce $\mathrm{N}$ excretion by ruminants (REDNEX)" and the Welsh Government.

\section{REFERENCES}

Allison, G. G., C. Morris, E. Hodgson, J. Jones, M. Kubacki, T. Barraclough, N. Yates, I. Shield, A. V. Bridgwater, and I. S. Donnison. 2009a. Measurement of key compositional parameters in two species of energy grass by Fourier transform infrared spectroscopy. Bioresour. Technol. 100:6428-6433.

Allison, G. G., S. C. Thain, P. Morris, C. Morris, S. Hawkins, B. Hauck, T. Barraclough, N. Yates, I. Shield, A. V. Bridgwater, and L. S. Donnison. 2009b. Quantification of hydroxycinnamic acids and lignin in perennial forage and energy grasses by Fourier-transform infrared spectroscopy and partial least squares regression. Bioresour. Technol. 100:1252-1261.

Andres, S., A. Calleja, S. Lopez, J. S. Gonzalez, P. L. Rodriguez, and F. J. Giraldez. 2005a. Prediction of gas production kinetic parameters of forages by chemical composition and near infrared reflectance spectroscopy. Anim. Feed Sci. Technol. 123:487-499.

Andres, S., A. Calleja, S. Lopez, A. R. Mantecon, and F. J. Giraldez. 2005b. Nutritive evaluation of herbage from permanent meadows by near-infrared reflectance spectroscopy: 2. Prediction of crude protein and dry matter degradability. J. Sci. Food Agric. $85: 1572-1579$

Andueza, D., F. Picard, M. Jestin, J. Andrieu, and R. Baumont. 2011. NIRS prediction of the feed value of temperate forages: Efficacy of four calibration strategies. Animal 5:1002-1013.
AOAC International. 2005. Official Methods of Analysis. 18th ed. AOAC International, Arlington, VA.

ARC. 1984. The Nutrient Requirements of Ruminant Livestock. Suppl. 1. CAB International, Wallingford, UK.

Barth, A., and C. Zscherp. 2002. What vibrations tell us about proteins. Q. Rev. Biophys. 35:369-430.

Berzaghi, P., J. S. Shenk, and M. O. Westerhaus. 2000. LOCAL prediction with near infrared multi-product databases. J. Near Infrared Spectrosc. 8:1-9.

Chauvin, J. V., and J. E. Field. 1992. Keeping the "un" in unknowns in qualitative identification exercises using FTIR. J. Chem. Educ. 69:661.

Danfaer, A., P. Huhtanen, P. Uden, J. Sveinbjornsson, and H. Volden. 2006. The Nordic Dairy Cow Model, Karoline - Description. Chapter 33 in Nutrient Digestion and Utilization in Farm Animals: Modelling Approaches. CABI Publishing, Wallingford, UK.

He, Y., X. Li, and X. Deng. 2007. Discrimination of varieties of tea using near infrared spectroscopy by principal component analysis and BP model. J. Food Eng. 79:1238-1242.

Hedqvist, H., and P. Uden. 2006. Measurement of soluble protein degradation in the rumen. Anim. Feed Sci. Technol. 126:1-21.

Herrero, M., N. S. Jessop, R. H. Fawcett, I. Murray, and J. B. Dent. 1997. Prediction of the in vitro gas production dynamics of kikuyu grass by near-infrared reflectance spectroscopy using spectrally-structured sample populations. Anim. Feed Sci. Technol. 69:281-287.

Hoffman, P. C., N. M. Brehm, L. M. Bauman, J. B. Peters, and D. J. Undersander. 1999. Prediction of laboratory and in situ protein fractions in legume and grass silages using near-infrared reflectance spectroscopy. J. Dairy Sci. 82:764-770.

Hvelplund, T. 1985. Digestibility of rumen microbial protein and undegraded dietary protein estimated in the small intestine of sheep and by in sacco procedure. Acta Agric. Scand. 25:132-144.

Hvelplund, T., J. Madsen, and M. R. Weisbjerg. 2003. Protein evaluation. Pages 583-602 in Proteinvurdering. DJF Rapport, Husdyrbrug (No. 53). DJF Rapport, Husdyrbrug, Danmarks JordbrugsForskning, Foulum, Denmark.

Hvelplund, T., and M. R. Weisbjerg. 2000. In situ techniques for the estimation of protein degradability and postrumen availability. Pages 233-258 in Forage Evaluation in Ruminant Nutrition. D. I. Givens, E. Owen, R. F. E. Axford, H. M. Omed, ed. CAB International, Wallingford, UK.

Krämer, M., P. Nørgaard, P. Lund, and M. R. Weisbjerg. 2013. Particle size alterations of feedstuffs during in situ neutral detergent fiber incubation. J. Dairy Sci. 96:4601-4614.

Lammers, K., G. Arbuckle-Keil, and J. Dighton. 2009. FT-IR study of the changes in carbohydrate chemistry of three New Jersey pine barrens leaf litters during simulated control burning. Soil Biol. Biochem. 41:340-347.

Lee, M. R. F., J. K. S. Tweed, and M. L. Sullivan. 2013. Oxidation of ortho-diphenols in red clover with and without polyphenol oxidase (PPO) activity and their role in PPO activation and inactivation. Grass Forage Sci. 68:83-92.

Madsen, J., T. Hvelplund, M. R. Weisbjerg, J. Bertilsson, I. Olsson, R. Sprndly, O. M. Harstad, H. Volden, M. Tuori, T. Varvikko, P. Huhtanen, and B. L. Olafsson. 1995. The AAT/PBV protein evaluating system for ruminants: A revision. Nor. J. Agric. Sci. 19(Suppl.):1-37.

Mathison, G. W., H. Hsu, R. Soofi-Siawash, G. Recinos-Diaz, E. K. Okine, J. Helm, and P. Juskiw. 1999. Prediction of composition and ruminal degradability characteristics of barley straw by near infrared reflectance spectroscopy. Can. J. Anim. Sci. 79:519-523.

Mentink, R. L., P. C. Hoffman, and L. M. Bauman. 2006. Utility of near-infrared reflectance spectroscopy to predict nutrient composition and in vitro digestibility of total mixed rations. J. Dairy Sci. $89: 2320-2326$.

NRC. 2001. Nutrient Requirements of Dairy Cattle. 7th rev. ed. National Academies Press, Washington, DC.

Ohlsson, C., L. P. Houmoller, M. R. Weisbjerg, P. Lund, and T. Hvelplund. 2007. Effective rumen degradation of dry matter, crude protein and neutral detergent fibre in forage determined by near 
infrared reflectance spectroscopy. J. Anim. Physiol. Anim. Nutr. (Berl.) 91:498-507.

Ørskov, E. R., and I. McDonald. 1979. Estimation of protein degradability in the rumen from incubation measurements weighted according to rate of passage. J. Agric. Sci. 92:499-503.

Schmidt, K. S., and A. K. Skidmore. 2001. Exploring spectral discrimination of grass species in African rangelands. Int. J. Remote Sens. 22:3421-3434.

Shenk, J. S., and M. O. Westerhaus. 1994. The application of near infrared reflectance spectroscopy (NIRS) to forage analysis. Pages 406-499 in Forage Quality Evaluation and Utilization. Am. Soc. Agron., Madison, WI.

Valdes, E. V., L. G. Young, S. Leeson, I. McMillan, F. Portela, and J. E. Winch. 1985. Application of near infrared reflectance spectroscopy to analyses of poultry feeds. Poult. Sci. 64:2136-2142.

Van Duinkerken, G., M. C. Blok, A. Bannink, J. W. Cone, J. Dijkstra, A. M. Van Vuuren, and S. Tamminga. 2011. Update of the Dutch protein evaluation system for ruminants: The DVE/OEB system. J. Agric. Sci. 149:351-367.

Verite, R., and J. L. Peyraud. 1989. Protein: The PDI system. Ruminant Nutrition: Recommended Allowances and Feed Tables. R. Jarrige, ed. John Libbey Eurotext, Paris, France.

Williams, P. C. 1987. Variables affecting near-infrared reflectance spectroscopic analysis. Pages 143-168 in Near-Infrared Technology in the Agricultural and Food Industries. Am. Assoc. Cereal Chem., St Paul, MN.

Williams, P. C., and D. C. Sobering. 1996. How we do it: A brief summary of the methods we use in developing near infrared calibrations. Pages 185-188 in Near Infrared Spectroscopy: The Future Waves. A. M. C. Davies and P. C. Williams, ed. NIR Publications, Chichester, UK.

Williams, P. C., and P. M. Starkey. 1980. Influence of feed ingredients upon the prediction of protein in animal feed-mixes by near-infrared reflectance spectroscopy. J. Sci. Food Agric. 31:1201-1213. 